\title{
Hidden association of knee-related disability with physical activities among community-dwelling older male Saudi Arabians with knee osteoarthritis
}

\author{
Mahamed Ateef* \\ Department of Physical Therapy and Health Rehabilitation, CAMS, Majmaah University, Al Majma'ah-11952, Kingdom of Saudi Arabia
}

\begin{abstract}
Introduction: The impact of knee osteoarthritis (OA) on physical activities of daily life was studied extensively among the elderly across the globe but not well understood in the Saudi Arabian populace with cultural consideration. This paper assessed the association between knee flexion range of motion (ROM) and ritual physical activities among elderly males due to knee OA.

Methods: A cross-sectional study with a sample of 139 males aged 56-74 years diagnosed with knee OA recruited at prayer places. The subjective evaluation was carried using a disease-specific Arabic knee physical functional questionnaire Knee injury and OA Outcome Score-Physical Function Short form (KOOS-PS), and the anthropometric measure of knee flexion ROM was objectively measured by a manual goniometer.

Results: The mean and standard deviation of the study sample age, height, weight, and body mass index were $66.9 \pm$ 4.09 years, $158.4 \pm 6.1 \mathrm{~cm}, 74.6 \pm 7.1 \mathrm{~kg}$, and $29.6 \pm 1.9 \mathrm{~kg} / \mathrm{m}^{2}$, respectively. The mean, standard deviation and median of the knee flexion ROM and Arabic-KOOS-PS Questionnaire score were $100.7 \pm 7.9,101.5$ and $12.9 \pm 13.7,13.4$. The non-parametric Spearman correlation coefficient between the knee stiffness and KOOS-PS physical activities resulted very strong positively correlation, $r=0.967$.
\end{abstract}

Conclusion: A strong positive correlation has been found between hidden knee disability and ritual physical activities among male cohorts in Saudi cultural community with knee OA.

Keywords: Osteoarthritis; knee; geriatrics; physical activity; disability; evaluation

\section{INTRODUCTION}

In 2020, it was estimated by the World Health Organization (WHO) that $15 \%$ of world population (over 1 billion) lives with some form of disability and $2-4 \%$ experience significant difficulty during physical activities with the ageing process and chronic health conditions which lead to increase in the rate of disability, and the worst affected are older people (1). "A disability is any condition of the body or mind (impairment) that makes it more difficult for the person with the condition to do certain activities (activity limitation) and interact with the world around them" (participation restrictions) (2). A person is generally considered disabled in the family and community when the disability is apparent to the eye. A person with disability resulting from a chronic disease sometimes may visually appear normal but faces difficulty performing task specific physical activities. The individuals

Corresponding author: Mahamed Ateef, Department of Physical Therapy and Health Rehabilitation, CAMS, Majmaah University, Al Majma'ah-11952, Kingdom of Saudi Arabia. E-mail: m.jeelani@mu.edu.sa

Submitted: 02 August 2021/Accepted: 30 December 2021

with disability may sometimes be unaware of their disability status or do not appreciate it until they discover it accidentally or they go through specific tasks. Most of the extended families have a disabled person, and a normal person takes care of them (1). Knee osteoarthritis (OA), being a chronic and one of the ten diseases in developed countries has been recorded as $9.6 \%$ and $18 \%$ in men and women over 60 years respectively. $80 \%$ of them have limited movement and $25 \%$ are unable to perform their major physical activities of life (3). Recent studies in Middle-east in the year 2020 have concluded that there was an impact of culture on health and effects of OA on physical activity limitation, participation, and religious activities (4). One Saudi-based study has stated that Muslim worshipers in Saudi society who could not perform the prayers on the floor which actually requires full flexion of the knee joints, have adapted to chair usage to offer the prayers due to their knee pain caused by OA (5). OA commonly affects the movable as well as weight bearing joints (6).

Data provided by United Nations stated that the current population count of Saudi Arabia is 3,528,839 as on May 19, 2021 (7). Approximately, 71.72\% were aged between 15 and 64 years, and about $3.41 \%$ were aged above 65 years (8). 
General Authority of Statistics, 2017 Saudi Arabia has stated that male Saudi population $(38,577) 65$ years and above had mild to severe difficulty in walking and climbing stairs (9). According to the WHO report on Saudi Arabia, the mean life expectancy was 74.9 years in 2016 (2). In a preliminary report of the World Health Survey, 2019 conducted by Ministry of Health, Saudi Arabia has stated that the general health status reported that the difficulty with moving around and participation in the community declined as the age increased (10). Social welfare system in the Kingdom of Saudi Arabia has been said to be strong enough toward its vision 2030 with various health and social care policies laid down by the "Ministry of Human Resources and Social Development" (11). Saudi health literature stated that the road traffic accidents, head and spinal cord injuries and children with cerebral palsy have been the main contributing factors and causes of chronic disability in Saudi Arabia (12). One recent review stated that there was a paucity of literature on disability and an estimated figure of $0.8 \%$ in Saudi population has disability (13). It has been well explained that there is a progressive pain and decline in physical activities thereby increasing deformities and disabilities among knee OA population (6). A current randomized controlled trial concluded that the progressive resistance strength training in non-weight bearing positions among knee OA patients is helpful in improving quality of life (14). A study in the year 2000 by Steultjens et al. and associates has concluded that the knee flexion range of motion (ROM) was a strong determinant factor and is associated with disability (15). Recent studies in Saudi Arabia have concluded that the severe knee OA patients have worse knee pain and declined quality of life $(5,16)$.

The impact of knee OA on physical activities of daily life was studied extensively among elderly across the globe but not well understood in the Saudi Arabian populace with regard to subjectively assessed knee disability and objectively measured flexion knee ROM in population who perform the ritual acts such as 5 times daily prayers in which normal to extreme joint movements are involved. The author hypothesizes that the unnoticed knee joint stiffness/reduced knee flexion ROM has an association with the increasing severity of knee related disability assessed among knee OA patients in Saudi Arabia. The aim of the study was to explore whether the hidden knee stiffness is associated with the daily ritual physical activities among elderly mobile males with knee OA in Saudi Arabic ethnicity. The objective of the study was to determine whether there was an impact of objectively measured knee ROM on subjectively assessed knee disability among elderly male with knee OA.

\section{METHODS}

The sample for this present study $(n=139)$ was collected by a convenience sampling method of cross-sectional observational study design. The participants (aged above 55 years) recruited were male adults with knee OA who were otherwise mobile and managed to visit outdoor activities in the Governorate of Al-Majmaah, Riyad Province, Kingdom of Saudi Arabia. The sample was targeted in the community participation such as at prayer houses (Mosques). A formal face to face interview was conducted soon after the prayers. On an initial contact with them, the subjects were asked about any knee difficulty while offering their prayers. Inclusion criteria, elderly male individuals with knee OA who were otherwise mobile and actively participated in the community. Exclusion Criteria, knee replacement, pre-patellar bursitis, old tibia fractures with a history of a 6-month duration, rheumatoid arthritis and variants of arthritis, old stroke patients, various hip conditions, knee OA along with hip OA and surgeries including knee replacement, morbid obesity, and various neurological disorders were excluded. On initial interview, most of the subjects reported that they were pre diagnosed with knee $\mathrm{OA}$ and faced difficulty in bending their knees.

After taking the history, it was decided to evaluate their knee problems both subjectively using a well-validated knee specific health questionnaire Knee injury and OA Outcome Score Physical Function Short form (KOOS-PS) where a lower score indicates a higher level of disability and vice versa, and objectively by measuring their knee joint flexion ROM where the position of the patient was supine lying as per patient convenience and then the active knee flexion ROM was measured using manual goniometer. The study protocol was explained to the subjects. Then the study participants were asked for a written informed consent form before the start of the initial physical examination and followed by the actual study protocol. Due to the fact that all of them were already diagnosed with knee OA, it was decided to re-confirm the diagnosis based on the standard American College of Rheumatology criteria (17). Among 139 initially interviewed subjects, 88 (63.3\%) were affected bilaterally while 53 were more affected by the right knee (Grade $3 \mathrm{OA}$ ) than by the left knee (Grade $3 \mathrm{OA}$ ) and 35 were more affected by the left knee (Grade $2 \mathrm{OA}$ ) than by the right knee (Grade $2 \mathrm{OA}) ; 51$ (36.7\%) were unilaterally affected $\mathrm{OA}$ where 36 were affected by the right knee (Grade $2 \mathrm{OA}$ ) and 15 were affected by the left knee (Grade 2 OA). Participants who met the inclusion criteria were asked to fill the questionnaire after making an attempt to sit on the floor to recollect the perception of the accurate difficulties and to avoid the recall bias.

The study sample size for this study design was obtained by calculating the formula based on the previous cross-sectional studies and a sample of 139 subjects extracted from the formula $(\mathrm{n}=\mathrm{z} \alpha 2 \mathrm{p}(1-\mathrm{p}) / \mathrm{d} 2)$. A total of 139 adult males (aged above 55 years) were randomly chosen from 47 Mosques (places of worship).

The data was collected from January to March, 2021 in the city of Al-Majmaah, Riyad Province, Saudi Arabia.

KOOS-PS Saudi Arabic Version was obtained from the domains of function, daily living and sports and recreational activity subscales of long scale KOOS (18). This scale is intended to measure the different levels of individual's difficulty experienced during the daily activity due to their ailments with the knee. This short form with fewer items has an advantage to limit responder burden and is preferable in special populations such as the elderly and relevant to the people with a range of knee problems. It has seven items such as (1) "rising from bed," (2) "putting on socks/stockings," (3) "rising from sitting," (4) "bending to floor," (5) "twisting/pivoting on your injured knee," (6) "Kneeling," (7) "Squatting” (koos.nu). The measurement 
properties of the KOOS-PS are considered reliable and valid (19). The Arabic version of KOOS-PS was used in this study to bring out their hidden knee difficulties during physical activities which would provide a comprehensive information relevant to their disability.

Goniometer is generally used by related health care professionals to measure the knee flexion ROM. Review board of Majmaah University approved the study where the study was carried out. This research was done based on the principles laid by declaration of Helsinki (Revised 2013) and the Council for International Organizations of Medical Sciences guidelines, International ethical guidelines for health-related research involving humans (2016). The data of participants of the study were maintained confidential.

Obtained patient data were analyzed using Statistical Package for the Social Sciences Version. Descriptive statistics were determined for demographic characteristics such as age, height, weight and body mass index (BMI), objectively measured knee flexion ROM and for overall KOOS-PS score as well as for individual self-rated items. Non-parametric Spearman's Correlation was generated for the knee flexion ROM and KOOS-PS self-rated outcome score as well as for each item.

\section{RESULTS}

The demographic characteristics of the sample $(n=139)$ are presented in Table 1 which displays the sample mean, standard deviation, median and minimum to maximum of the subjects age, height, weight and BMI of the elderly male who actively participated in the community.

Table 2 displays descriptive statistics such as mean, standard deviation, median and minimum to maximum of objectively measured knee flexion ROM of all the subjects with knee OA $(n=139)$ with the help of a manual goniometer along with self-rated knee physical disability disease-specific questionnaire, KOOS-PS.

Table 3 presents the correlation between the knee joint flexion ROM and total KOOS- Short form score. Results demonstrated that the knee joint flexion ROM stiffness was positively associated with self-rated knee physical disability. The overall score of the scale showed the worse physical activity due to the knee flexion movement restriction in knee OA among older adults.

TABLE 1. Demographic characteristics of the sample $(n=139)$

\begin{tabular}{lccc}
\hline Characteristics & Mean \pm SD & Minimum & Maximum \\
\hline Age in years & $66.9 \pm 4.09$ & 56 & 74 \\
Height in cm & $158.4 \pm 6.16$ & 150 & 170 \\
Weight in kg & $74.6 \pm 7.12$ & 65 & 83 \\
BMl & $29.6 \pm 1.9$ & 24 & 32
\end{tabular}

BMI: Body mass index, Cm: Centimeters, Kg: Kilograms, SD: Standard deviation

TABLE 2. Mean, standard deviation and median of knee-ROM and KOOS-PS score $(n=139)$

\begin{tabular}{lcccc}
\hline Variables & Mean \pm SD & Median & Minimum & Maximum \\
\hline ROM-knee flexion & $100.9^{0} \pm 7.9$ & 101.5 & 950 & $120^{\circ}$ \\
KOOS-PS SCORE & $12.9 \pm 13.7$ & 13.4 & 0 & 43
\end{tabular}

SD: Standard deviation, KOOS-PS: Knee injury and osteoarthritis outcome score physical function short form, ROM: Range of motion
Table 4 results demonstrated that the knee joint flexion ROM stiffness involving the "squatting activity" item was positively associated with self-rated knee physical disability. The "squatting activity" score of the scale showed the worse physical activity due to the knee flexion movement restriction of the knee joint in knee OA among older adults. The correlation coefficient was found to have a very strong positive correlation between the two measured variables.

Table 5 result showed that the knee joint flexion ROM stiffness involving the "kneeling activity/sitting" was positively associated with self-rated knee physical disability. The "kneeling activity" item score of the scale showed the worse physical activity due to the knee flexion movement restriction among older adults. The correlation coefficient was found to have very strong positive correlation between the two measured variables.

Table 6 depicted the correlation between flexion ROM and individual items of KOOS-PS short form scores. A positive

TABLE 3. Spearman correlation coefficient (Spearman's Rho) of knee flexion ROM and self-rated disability of KOOS-PS total score

\begin{tabular}{lcr}
\hline Variables & Spearman's Rho & $p$-value \\
\hline ROM- Knee flexion & $0.857^{\star *}$ & $<0.001$ \\
Total KOOS-PS SCORE & & \\
\hline
\end{tabular}

The statistical significance is marked with "*". ${ }^{* *}$ Correlation is significant at 0.05 . KOOS-PS: Knee injury and osteoarthritis outcome score physical function short form; ROM: Range of motion

TABLE 4. Spearman correlation coefficient (Spearman's Rho) of self-rated disability of KOOS-PS scale-squatting Item with knee ROM

\begin{tabular}{lcc}
\hline Variables & Spearman's Rho & $p$-value \\
\hline ROM-knee flexion & $0.967^{* \star}$ & $<0.001$ \\
KOOS-PS squatting item & &
\end{tabular}

KOOS-PS squatting item

The statistical significance is marked with "*”. ${ }^{* *}$ Correlation is significant at 0.05 . KOOS-PS: Knee injury and osteoarthritis outcome score physical function short form; ROM: Range of motion

TABLE 5. Spearman correlation coefficient (Spearman's Rho) of self-rated disability of KOOS-PS scale-kneeling item with knee ROM

\begin{tabular}{lcc}
\hline Variables & Spearman's Rho & $p$-value \\
\hline ROM-knee flexion & $0.842^{* *}$ & $<0.001$ \\
KOOS-PS kneeling item & & \\
\hline
\end{tabular}

The statistical significance is marked with "*". ${ }^{* *}$ Correlation is significant at 0.05. KOOS-PS: Knee injury and osteoarthritis outcome score physical function short form; ROM: Range of motion

TABLE 6. Spearman correlation coefficient (Spearman's Rho) of self-rated disability of KOOS-PS individual items with knee flexion ROM

\begin{tabular}{llcl}
\hline Variable & $\begin{array}{l}\text { Individual } \\
\text { KOOS-PS Items }\end{array}$ & Spearman's Rho & $p$-value \\
\hline Knee flexion-ROM & KOOS-PS-1 & $0.733^{* *}$ & $<0.001$ \\
& KOOS-PS-2 & $0.848^{* *}$ & \\
& KOOS-PS-3 & $0.849^{* *}$ & \\
& KOOS-PS-4 & $0.778^{* *}$ & \\
& KOOS-PS-5 & $0.681^{* *}$ & \\
& KOOS-PS-6 & $0.842^{* *}$ & \\
& KOOS-PS-7 & $0.967^{* *}$ & \\
\hline
\end{tabular}

The statistical significance among grade groups is marked with "*". ${ }^{* *}$ Correlation is significant at 0.05 . KOOS-PS: Knee injury and osteoarthritis outcome score physical function short form; ROM: Range of Motion 
correlation was found between the knee joint flexion-ROM and all the individual items such as "rising from bed," "putting on socks/stockings," "rising from sitting," "bending to floor," "twisting/pivoting on your injured knee," "Kneeling," "Squatting." The Squatting activity showed the worse physical activity restriction of the knee flexion movement among older adults with a very strong positive correlation supporting the hypothesis of the study.

\section{DISCUSSION}

There were studies done previously to relate the knee ROM with self-rated knee disability in knee OA population from various settings such as pre-operative evaluation in surgeries (20) and in randomized control trials involving different interventions (21). To the author's knowledge, this is the first study reporting the hidden knee disability due to knee OA associated with (impact on) specific physical activities such as squatting (Sujud-prostration) and kneeling (Tashahud-kneel sitting) poses needed to be adapted during prayers on the floor.

A present study had cross-sectionally evaluated the subjects for their physical activity, quality of life using only subjective outcome measures and found the reason for adaptation of an alternative method of chair usage to offer the prayers (5). In the present study, the author has correlated the objective knee disability (declined knee ROM) using a goniometer with subjective outcome physical activities using a self-rated questionnaire where the subjects faced physical difficulties during prayers (Salat) in an authentic prayer procedure which requires various knee range of movements. Their disability is considered latent/hidden because they did not appreciate the pain or their inability to perform knee specific physical activities during daily prayers.

The novelty of the current study was to correlate the knee flexion ROM with the self-rated knee activities among elderly male Muslims who were otherwise mobile and independent but were religious and have been offering prayers 5 times every day by choosing an alternative method of sitting on a chair due to knee OA. Mactaggart et al. in 2016 have stated that the disability could be better evaluated using self-rated scales and physical examination in knee OA population (22). KOOS-PS questionnaire is one such a scale extracted from KOOS long form where the maximal score means no symptoms and the minimal score means maximum disability (23).

The joint stiffness in terms of disability has been observed in knee OA (15). Foo and his teammates in 2017 have found extreme disability using a subjective measure (24). Alkan et al. in 2014 have found a positive association between knee OA and disability (25). A few studies have reported that the knee stiffness is a determinant factor for activities of daily life $(25,26)$. Moreover, some amount of ROM is required to obtain adequate functional tasks such as extreme knee flexion (27). One study reported that there was a moderate relationship between the knee $\mathrm{ROM}<110^{\circ}$ and the limitation of activities and participation restrictions in the OA knee population who were undergoing knee replacement (20). The current study has found a strong positive correlation between the knee flexion
ROM and self-rated KOOS-PS short form score where the declined score indicates an increased disability, that is, as the stiffness increased, the disability increased. The mean ROM of the study by Wyldea et al., 2014 was $<110^{\circ}$ which shows the moderate association between the two variables (20) whereas in current study, the mean flexion ROM was $100.9^{\circ}$ and found the correlation with the self-rated knee disability.

In the Wyldea et al. study, the mean ROM was $<110^{\circ}$ which caused the moderate correlation because their population was indicated for joint replacement surgery where such patients experienced severe pain and joint stiffness with grade 3 or 4 knee OA (20). In the present study, the participants attained an alternative method of chair usage to accomplish the required physical activities during prayer procedure to overcome the knee squatting and kneeling difficulties. When the participants were asked to make a formal sitting which is an authentic way of offering prayer on the floor before filling the questionnaire, the restricted knee flexion ROM would have been appreciated by them and the participants would have chosen their difficulty levels which would have resulted in a strong positive correlation depicting the impact of hidden knee disability on ritual physical activities.

In general, the patients tend to avoid the joint pain and stiff positions during activities of daily living in order to not appreciate the symptoms (28). This avoidance nature of the knee OA patients further leads to the enhancement of the stiffness symptoms thereby muscle atrophy proceeding to knee disability (29). One study has reported that the decreased ROM caused an increased locomotor disability where they found a strong association between ROM and locomotor disability (30). This is similar to the findings of the current study. Steultjens et al., in 2000 have concluded that the restricted joint ROM was said to be an important risk factor for the locomotor disability in knee OA patients (15).

When the flexion ROM was correlated with the individual items of the questionnaire, there was a high correlation between knee flexion ROM and squatting as well kneeling positions. This correlation was generated because these two action tasks were involved during the prayers several times a day. As mentioned earlier, the avoidance nature of knee OA patients was to not appreciate the pain and stiffness in these two actions, the correlation was high as these actions involved extreme knee flexion movements (29). A study in the year 2019 in Saudi Arabia has concluded that there was a correlation between movement difficulties and the affected joints with knee OA (31). One performance-related study using the physical activity restriction scale stated that the patient-rated levels of dysfunction have a positive correlation with the disability due to knee OA (32).

When compared to the study done by Wyldea et al., a decreased $\mathrm{ROM}<110^{\circ}$ knee flexion was significantly correlated with WOMAC- function (20) which was also supported by the findings of the current study with knee flexion ROM with squatting, kneeling and overall tasks. One recent study in the Kingdom of Saudi Arabia by Mohammed and associates in 2018, have concluded that their participants were not aware of disabilities associated with knee OA (33). Due to the lack of knowledge of knee OA associated disability and avoidance nature, disability level of the cohorts 
of the current study might have deteriorated and the so called hidden disability has been neglected by the worshippers because of which the elderly Muslim male populace were unable to sit on the ground to offer the prayers and acquired an alternate method of chair adaptability to offer the prayers (5).

A recent longitudinal study by Ho et al. in 2020 have found that the decreased "functionality and increased disability" in subjects who were scheduled for total knee arthroplasty, where their self-rated disease specific WOMAC functional score was significantly showing an increased disability on follow-up and greater disability on $2^{\text {nd }}$ year follow-ups (34). When compared to initial score $p<0.05$, their self-rated disability levels over 2-years follow-up and their generic short form-36 v2 score showed a deterioration of physical function; also stated that the severe knee stiffness caused more disability due to adapted sedentary lifestyle, creating a vicious cycle (35-39) which supports our study with selfrated knee disability and consistent with overall KOOS-PS mean score of 12.9 (lowest score indicates functional loss/ disability).

This self-rated knee disability results of the current study were also in line with the study done by Kapstad et al. in the year 2007 showing the deterioration of physical function, where the mean age in both studies were around 67 , 69 years, WOMAC score was correlated with physical function in patients before knee replacement surgery (35). A study by Desmeules et al. in 2010 stated that the disease-specific WOMAC physical function score and generic SF-36 physical role scores deteriorated in patients who waited for 12 months for Total Knee Replacement surgery (39). A cohort study investigated worst functional outcomes in subjects before and after TKR who waited for 2 years (40). Although our subjects were functionally mobile and used to visit the Mosque 5 times a day for their daily prayers with adapting a chair, a hidden disability has been observed among them as they were unable to squat and kneel down on the ground as followed in an authenticated prayer practice due to knee stiffness which was positively associated with self-rated disability. Subjects had a mean history of 7 months- 9 years of chair usage which was also a reason for high correlation between the variables enhancing the vicious cycle (5).

This study shows a high level of significance as the subjects of this study belong to a very religious and cultural society of Saudi Arabia where most of them offer prayers 5 times every day which includes positions such as squatting and kneel sitting on the ground where their pain and knee stiffness due to knee OA would not have allowed them to sit on the ground, thus the patients had to adapt to use a chair to offer the prayer as an alternate method (5). As hypothesized, the correlation between reduced knee flexion ROM and self-rated disability which resulted in high significance, it is believed that the subjects with the knee OA would have appreciated knee disability while performing the prayers thus adapted a modified physical activity. One Japanese cohort study has concluded that the physical activities were severely affected due to physical functional impairment in knee OA (41) which supports the present study where the ritual physical activities (prayers) were positively correlated with knee related disability among elderly in Saudi
Arabia where the elderly people have adapted to modified physical activities using the chair to offer the prayers with knee OA. This study suggests to focus on such kind of hidden impact of knee disability on physical activities among Saudi Arabians using a comprehensively validated disability specific construct questionnaire/subjective tool along with evaluation of different radiographic grades of knee OA patients by health researchers, professionals and social care policymakers in the Saudi community to work in coordination to overcome their hidden knee-specific disability worsening to handicap thereby a better quality of life.

\section{Study limitations and recommendations}

As per the Saudi Arabian cultural rules, male physical therapists are not allowed to examine and treat female subjects hence, only males were taken. In patients with knee OA, the KOOS-PS appears too restricted in item content to provide a comprehensive estimate of lower extremity functional status level. To improve mobility, knee OA patients should follow the instructions of daily care as described in a current randomized controlled trial (14).

\section{CONCLUSION}

A strong positive correlation has been found between hidden knee disability and ritual physical activities among male cohorts in Saudi cultural community with knee OA. Hence, elderly Saudi knee OA patients found it difficult to offer prayers on floor due to their knee disability.

\section{ACKNOWLEDGMENT}

The author specially thank all the "priests" at different mosques for their kind cooperation to allow and collect the data and the Author is thankful to the Deanship of Scientific Research at Majmaah University, Al Majma'ah, 11952, Saudi Arabia for supporting this work.

\section{CONFLICT OF INTERESTS}

Authors declare no conflict of interest.

\section{REFERENCES}

1. World Health Organization, Disability and Health. Disability and Health. World Health Organization; 2020. Available from: https://www.who.int/news-room/fact-sheets/ detail/disability-and-health Accessed 29 Oct. 2021.

2. World Health Organization. International Classification of Functioning, Disability and Health (ICF) external icon. Geneva: World Health Organization; 2021. Available from: http://apps.who.int/iris/bitstream/handle/10665/42407/9241545429.pdf;jsessionid=195C79FAAA0564FF116926A6F824951F?sequence=1 Accessed 29 Oct. 2021.

3. Heidari B. Knee osteoarthritis prevalence, risk factors, pathogenesis and features: Part I. Caspian J Intern Med 2011;2(2):205-12.

4. Al-Khlaifat L, Okasheh R, Muhaidat J, Hawamdeh ZM, Qutishat D, Al-Yahya E, et al. Knowledge of knee osteoarthritis and its impact on health in the Middle East: Are they different to countries in the developed world? A qualitative study. Rehabil Res Pract 2020;7:9829825.

https://doi.org/10.1155/2020/9829825

5. Ateef M, Alqahtani MM, Alzhrani M, Alshewaier S. Physical function and quality of life and modification of authentic Islamic prayer procedure by osteoarthritis knee patients in Saudi Arabia: A cross-sectional study. J Relig Health 2021;60:764-73. https://doi.org/10.1007/s10943-019-00878-8

6. Zhang Y, Jordan JM. Epidemiology of osteoarthritis. Clin Geriatr Med 2010;26:355-69. https://doi.org/10.1016/j.cger.2010.03.001

7. World Population, Saudi Arabia Population; 2021. Available from: https://www.worldometers.info/world-population/saudi-arabia-population Accessed 30 Oct. 2021.

8. O' Neill A. Age Structure in Saudi Arabia; 2021. Available from: ht t p s : / w w w. 
statista.com/statistics/262478/age-structure-in-saudi-arabia Accessed 3 Oct. 2021

9. General Authority for Statistics-Elderly Survey; 2017. Available from: https://www.stats.gov.sa/en/909 Accessed 2 Nov. 2021.

10. KSAWHS-Ministry of Health-Saudi Arabia; 2021. Available from: https://www.moh gov.sa/en/Ministry/Statistics/Population-Health-Indicators/Documents/World-HealthSurvey-Saudi-Arabia.pdf Accessed 2 Nov. 2021

11. Social Welfare System; 2021. Available from https://www.my.gov.sa/wps/portal/snp/aboutksa/SocialProtection Accessed 3 Nov. 2021

12. Centre for Disease Control and Prevention. Central Department of Statistics and Information (Saudi Arabia). Atlanta, Georgia: Centre for Disease Control and Prevention; 2021. Available from: https://www.cdc.gov/ncbddd/disabilityandhealth/disability.html Accessed 3 Nov. 2021.

13. Al-Jadid MS. Disability in Saudi Arabia. Saudi Med J 2013;34(5):453-60.

14. Rafiq MT, A Hamid MS, Hafiz E. Effect of progressive resistance strength training on body mass index, quality of life and functional capacity in knee osteoarthritis: A randomized controlled trial. J Multidiscip Healthc 2021;14:2161-8.

https://doi.org/10.2147/JMDH.S317896

15. Steultjens MP, Dekker J, van Baar ME, Oostendorp RA, Bijlsma JW. Range of joint motion and disability in patients with osteoarthritis of the knee or hip. Rheumatol (Oxford) 2000;39(9):955-61.

https://doi.org/10.1093/rheumatology/39.9.955

16. Bindawas SM, Vennu V, Alfhadel S, Al-Otaibi AD, Binnasser AS. Knee pain and health-related quality of life among older patients with different knee osteoarthritis severity in Saudi Arabia. PLoS One 2018;13(5):e0196150.

https://doi.org/10.1371/journal.pone.0196150

17. Altman R, Asch E, Bloch D, Bole G, Borenstein D, Brandt K, et al. Development of criteria for the classification and reporting of osteoarthritis. Classification of osteoarthritis of the knee. Diagnostic and therapeutic criteria committee of the American rheumatism association. Arthritis Rheum 1986;29(8):1039-49.

https://doi.org/10.1002/art.1780290816

18. KOOS-PS; 2021. Available from: http://koos.nu [Last accessed on 2021 Jan 02].

19. Perruccio AV, Lohmander LS, Canizares M, Tennant A, Hawker GA, Conaghan PG, et al. The development of a short measure of physical function for knee $O A$ KOOS-Physical Function Short form (KOOS-PS) an OARSI/OMERACT initiative. Osteoarthritis Cartilage 2008;16(5):542-50.

https://doi.org/10.1016/j.joca.2007.12.014

20. Wylde V, Lenguerrand E, Brunton L, Dieppe P, Gooberman-Hill R, Mann C, et al. Does measuring the range of motion of the hip and knee add to the assessment of disability in people undergoing joint replacement? Orthop Traumatol Surg Res 2014;100(2):183-6.

https://doi.org/10.1016/j.otsr.2013.09.016

21. van Baar ME, Dekker J, Oostendorp RA, Bijl D, Voorn TB, Bijlsma JW. Effectiveness of exercise in patients with osteoarthritis of hip or knee: Nine months' follow up. Ann Rheum Dis 2001;60(12):1123-1130.

https://doi.org/10.1136/ard.60.12.1123

22. Mactaggart I, Kuper H, Murthy GV, Oye J, Polack S. Measuring disability in population based surveys: The interrelationship between clinical impairments and reported functional limitations in Cameroon and India. PLoS One 2016;11(10):e0164470. https://doi.org/10.1371/journal.pone.0164470

23. Guevara-Pacheco SV, Feican-Alvarado A, Delgado-Pauta J, Lliguisaca-Segarra A, Pelaez-Ballestas I. Prevalence of disability in patients with musculoskeletal pain and rheumatic diseases in a population from Cuenca, Ecuador. J Clin Rheumatol 2017;23(6):324-9.

https://doi.org/10.1097/RHU.00000000000000571

24. Foo CN, Manohar A, Rampal A, Lye MS, Sidik SM, Osman ZJ. Knee pain and functional disability of knee osteoarthritis patients seen at Malaysian government hospitals. Mal J Med Health Sci 2017;13:7-15

25. Alkan BM, Fidan F, Tosun A, Ardıçoğlu O. Quality of life and self-reported disability in patients with knee osteoarthritis. Mod Rheumatol 2014;24(1):166-71.

https://doi.org/10.3109/14397595.2013.854046
26. Lin YC, Davey RC, Cochrane T. Tests for physical function of the elderly with knee and hip osteoarthritis. Scand J Med Sci Sports 2001;11:280-6.

https://doi.org/10.1034/j.1600-0838.2001. 110505.x

27. Miner AL, Lingard EA, Wright EA, Sledge CB, Katz JN; Kinemax Outcomes Group. Knee range of motion after total knee arthroplasty: How important is this as an outcome measure? J Arthroplasty 2003;18:286-94.

https://doi.org/10.1054/arth.2003.50046

28. Evers AW, Kraaimaat FW, Geenen R, Bijlsma JW. Psychosocial predictors of functional change in recently diagnosed rheumatoid arthritis patients. Behav Res Ther 1998;36:179-93.

https://doi.org/10.1016/s0005-7967(98)00019-9

29. O'Reilly SC, Jones A, Muir KR, Doherty M. Quadriceps weakness in knee osteoarthritis: The effect on pain and disability. Ann Rheum Dis 1998;57(10):588-94. https://doi.org/10.1136/ard.57.10.588

30. Odding E, Valkenburg HA, Algra D, Vandenouweland FA, Grobbee DE, Hofman A. The association of abnormalities on physical examination of the hip and knee with locomotor disability in the Rotterdam study. Br J Rheumatol 1996;35(9):884-90. https://doi.org/10.1093/rheumatology/35.9.884

31. Mahfouz ME, Alharthi YF, Alzahrani M, Lmhmad M, Albarakati M, Eman A Osteoarthritis patient's comorbidity and lifestyle: A cross-sectional study on the Saudi population. Int J Med Dev Ctries 2019;3:363-9. https://doi.org/10.24911//JMDC.51-1545769494

32. Rejeski J, Ettinger WH, Schumaker JS. Assessing performance-related disability in patients with knee osteoarthritis. Osteoarthr Cartil 1995;3(3):157-67. https://doi.org/10.1016/s1063-4584(05)80050-0

33. Mukharrib MS, Al-Sharif MN, Alshehri TK, Shaker A. Knowledge of knee osteoarthritis among general population in Aseer Region. J Family Med Prim Care 2018;7(6):1385-9.

https://doi.org/10.4103/jfmpc.jfmpc_290_18

34. Ho KW, Pong G, Poon WC, Chung KY, Kwok YY, Chiu KH. Progression of health-related quality of life of patients waiting for total knee arthroplasty. J Eval Clin Pract 2021;27(1):69-74

https://doi.org/10.1111/jep.13388

35. Kapstad H, Rustøen T, Hanestad BR, Moum T, Langeland N, Stavem K. Changes in pain, stiffness and physical function in patients with osteoarthritis waiting for hip or knee joint replacement surgery. Osteoarthritis Cartilage 2007;15(7):837-43. https://doi.org/10.1016/j.joca.2007.01.015

36. Sale JE, Gignac M, Hawker G. The relationship between disease symptoms, life events, coping and treatment, and depression among older adults with osteoarthritis. J Rheumatol 2008;35(2):335-42.

37. Kim KW, Han JW, Cho HJ, Chang CB, Park JH, Lee JJ, et al. Association between comorbid depression and osteoarthritis symptom severity in patients with knee osteoarthritis. J Bone Joint Surg Am 2011;93(6):556-63.

https://doi.org/10.2106/JBJS.I.01344

38. Hawker GA, Gignac MA, Badley E, Davis AM, French MR, Li Y, et al. A longitudinal study to explain the pain-depression link in older adults with osteoarthritis. Arthritis Care Res (Hoboken) 2011;63(10):1382-90.

https://doi.org/10.1002/acr.20298

39. Desmeules F, Dionne CE, Belzile E, Bourbonnais R, Frémont P. The burden of wait for knee replacement surgery: Effects on pain, function and health-related quality of life at the time of surgery. Rheumatology (Oxford) 2010;49(5):945-54.

https://doi.org/10.1093/rheumatology/kep469

40. Fortin PR, Penrod JR, Clarke AE, St-Pierre Y, Joseph L, Bélisle P, et al. Timing of total joint replacement affects clinical outcomes among patients with osteoarthritis of the hip or knee. Arthritis Rheum 2002;46(12):3327-30.

https://doi.org/10.1002/art.10631

41. Sugai K, Michikawa T, Takebayashi T, Nishiwaki Y. Knee pain and future decline in higher-level functional competence in community-dwelling older Japanese: The Kurabuchi cohort study. Age Ageing 2020;49(1):592-8.

https://doi.org/10.1093/ageing/afaa024

\section{RELATED ARTICLES PUBLISHED IN JHSCI}

1. Bojičić S, Avdić D, Katana B, Jaganjac A, Mačak Hadžiomerović A. Efficiency of combined treatment and conventional physical treatment in bilateral knee arthrosis. JHSCl. $2013.25 ; 3(1): 70-4$ 